\title{
INFORMATION TECHNOLOGY AS ATECHNICAL RESOURCE FOR THE MEMORIES: MEMORIES OF UNATI-MARÍLIA IN THE VIRTUAL ENVIRONMENT
}

\author{
Simone Borges Paiva \\ University of São Paulo, São Paulo, São Paulo, Brazil \\ Maria Candida Soares Del-Masso \\ UNESP Sao Paulo State University, Marília, São Paulo, Brazil
}

\begin{abstract}
UNATI (Open University of the Third Age), UNESP, Marília campus, has offered subsidies for the development of this work aimed at researching the existing relationships between information mediation processes and technological devices, especially computers, assuming that reading practices and textual construction in online environments could help the "third age" population to have access to these devices, thus promoting digital inclusion in this group. Mediation was presented as an interventionist action that, by introducing an intermediate element in the learning process, causes a rupture in the ways of living and personal digital inclusion processes hitherto experienced. In the context of a workshop, we found out that there is a physical relationship between subjects and technological supports and such a contact proved to be necessary, considering that handling a computer required knowledge of procedures, thus furthering a logic of use. It turned out to be necessary to develop actions that would enable the handling of a computer so as to bring about acceptance of these supports. Accordingly, activities were developed so as to articulate reminiscent processes, memories of older adults, the writing down of such memories and the creation of a blog to bring enhanced visibility to the content produced by older people. Such actions have shown that remembering, writing down and posting can reshape not only social relations but somehow significantly promote digital inclusion among older adults.
\end{abstract}

Keywords: Information and Communication Technologies, UNATI, older adult, blog, Internet

\footnotetext{
Manuscript first received/Recebido em 01/03/2012 Manuscript accepted/Aprovado em: 22/12/2012

Address for correspondence / Endereço para correspondência

Simone Borges Paiva Master of Science in Information Science from UNESP, Marília campus. PHd student of Information Science at the Post-Graduation Program in Information Science, School of Communication and Arts - USP, São Paulo. E-mail: sibpaiva@usp.br
}

Maria Candida Soares Del-Masso, Faculty member at UNESP, Marília campus, Department of Special Education. Coordinator of the Central Groups of, UNATI (Open University of the Third Age) - UNESP - PROEX - Coordinator since 2004. Coordinator of UNATI - UNESP - Marília in the period of 19942010. Leader of the GEPIS (Research Group on Social Inclusion) / CNPq. E-mail: delmasso@marilia.unesp.br 


\section{INTRODUCTION}

What to do with all the things you do not know how to handle?, an elderly student muses revealing her uncertainties about the various technological devices currently available and often haunting those who have never been in contact with all these new media. This article aims to discuss the issues concerning sociocultural integration of men and women aged 60 and over in the context of Information Society.

Older adults experience life, the passing of time and the grasp on daily activities in a balanced, orderly, linear pace. Beauvoir (1990) argues that old age is not easily delimited due to the various perspectives comprising it, namely, the biological, chronological, social, emotional and professional aspects, among others.

Following the development of the so-called Information and Communication Technologies there has been a noticeable change in our modes of perception of the world, as things do not remain unchanged for long, and the present time is characterized by the urgency of the new. A question remains for older adults: how to behave in a context of constant change? What are the skills needed to interact with technological devices? To what extent are these resources necessary in the daily lives of older people? What strategies can be undertaken so as to facilitate access and use of technological resources, specifically computers?

The context of the UNATI (Open University of the Third Age), UNESP, Marília campus, has offered subsidies for the development of this work aimed at researching existing relationships between information mediation processes and technological devices, especially computers, assuming that reading practices and textual construction in on-line environments could help older adults to get hold of these devices, thus promoting digital inclusion in this group. Such an action was justifiable to the extent that men and women increasingly turn to the use of technologies in order to get updated and learn about these resources, assigning meaning to this action.

The UNATI was set up in 1993 at UNESP (Universidade Estadual Paulista), based on discussions held in the Senior Project implemented by PROEX ((Dean of University Extension), with the purpose of enabling access to public universities for the aging population, thus minimizing social exclusion among them. The underlying intent was to create a cultural and educational site for knowledge expansion, besides furthering lifelong learning through social interactions and the sharing of life experiences among participants of the UNATIs as well as undergraduate and postgraduate students from the various courses held at the UNESP campus, located in the State of São Paulo.

The UNATI-UNESP Central Groups, connected with PROEX, is corroborated and institutionalized by "ACT UNESP No. 191", dated May 7, 2001, as a result of the collective work developed in the various campuses of UNESP (DEL-MASSO: 2010). Currently, this group consists of 22 groups located in 21 campi of UNESP all over the State of São Paulo.

The UNATI at the College of Social Sciences and Philosophy, Marília campus, was one of the first to operate on an institutional basis. Its activities began in 1994 with the promotion of the Scientific Seminar on Universities of the Third Age; in March 1995, the first class for 40 old-age students was open for enrollments. By incorporating the problem currently facing older adults, the UNATI - UNESP - Marília Program aims to provide proper conditions for social and academic integration of older adults through 
social contact in an university environment.

In this study, we refer to Vygotsky and the way he attaches a historical process to the perception of contexts, which extend through sociocultural aspects and mediation actions that turn the subjects' development into a more complex one. We also refer to Almeida $J r$ and his contribution to the understanding of cultural activities in the context of Libraries and Information Science, offering subsidies for a broader perception about the symbolic exchanges ocurring between the subjects and the various informational supports.

The methodological path was structured so as to articulate the theoretical reflexion and the practical activities offered to the members of the Grupo de Leitura (a reading group) of UNATI - UNESP - Marília, men and women aged 60 and over. For a year, older adults attended weekly meetings to create a blog named Conto Prosa (short story and prose), a site designed for the dissemination of writings and literary discussions collectively framed within the Oficina de Leitura (a reading workshop). For data collection, we have applied action-research, and the mediation was presented as an interventionist action that, by introducing an intermediate element in the learning process, causes disruption in actions and reorganization aimed at restoring balance in learning.

In the context of the workshop, we found out that there is a physical relationship between the subjects and technological supports and, in such a relationship, we could observe that the contact proved to be necessary and physical handling enabled older adults to model the supporting tools, providing the characteristics that were most favorable to them. Such action remodels and updates men/women and reinvents the instrument, taking into account the actions undertaken, thus furthering digital inclusion in a group apparently shut out from digital media.

\section{THEORETICAL COURSE}

Some questions have risen from this research: how to treat concepts of mediation in an informational environment with the purpose of implementing strategies intended for the dissemination of information to users? First of all, we must understand that in a sociocultural approach the environment is filled with information that could be related to the stimuli the subject is exposed to.

Changes and actions performed by the subjects on information is directly linked to the level of development in which they find themselves. One cannot disregard environmental stimuli, or consider them a poor piece of information or one that could be rendered null. They will be reformulated when the subjects acquire the structure needed to think over the stimuli they are exposed to. As Almeida (2008a) suggests, "we understand information from the modification, the change, the reorganization, the restructuring, in short, the transformation of knowledge".

In the field of Information Science, the most recurring idea on the concept of information - the object of study for information scientists - refers to the ability of information to generate knowledge; whatever it is that generates knowledge can be considered information. However, we propose herein a different approach for treating the concept of information.

In his work, Almeida describes how the concept of information should be 
reformulated and revised within the field of Information Science. According to the author:

\begin{abstract}
We argue that information does not emerge as a fisnished product, it is neither anticipated nor predictable. Information represents the unknown. Therefore, it lies restless and as such it causes unrest, conflicts. Even though it is formed in the individual, it is dependent on the collective. Knowledge itself is dependent on the collective. (ALMEIDA: 2008b).
\end{abstract}

This is how we describe the sociocultural context of information, an interpretation we consider more appropriate for treating the concept of information, as it does not reject the various forms of stimuli generated and available in the environment and in the subjects. So, Giglio (2007) states that:

\begin{abstract}
In today's world, everything is conceptualized as information, from news headlines to the genetic code, from the color of food to the kind of sensation we experiment in our bellies when we are about to meet someone else. The most intriguing, however, is that we know that we will never know precisely what such countless information will be good for -

information which we must keep a watchful eye on - unless in the very instant we need it! Yet, this trait of contemporaneity keeps a remarkable correspondence with the nature of information when thought of in relation to the creative process. Creators never know what knowledge their minds will refresh at the moment an idea is being produced, since the choices among the range of information available is partly unconscious and intuitive.
\end{abstract}

The author reinforces the nature of the present moment, the instant the event occurs, the way the knowledge of the moment is being produced and informational influences are being restored from each subject. In that very instant, information must be taken as something that organizes and reorganizes itself acquiring meaning and significance based on the knowledge individuals keep at that moment vis-à-vis their life history and sociocultural context. This historical and sociocultural context, present in the concept of information advocated by Almeida, can also be found in Vygotsky (2000) who underscores history - the historical process each individual is bound to and its action/work relations - in the redesigning of content and the constant reorganization of environment and information, a diverse background that becomes increasingly complex as its parts keep growing.

To this extent, the mediation that belongs to this scenario is a mutual cooperation relationship, and those who realize the richness in this type of exchange do grow up. And how to bring these reflections to the field of Information Science? In particular, how to organize mediation activities that will assist in the process of digital inclusion?

From this perspective, some indications can already be commented taking into account a more versatile, more contextualized concept of information. Information can not be taken just as the element of surprise that only happens in the subject's routine contact with informational stimuli. On commenting about the concept of information, Almeida emphasizes that: 
Contrary to the concept largely accepted in the area, information is being employed as a source of conflicts, since only these enable the transformation of knowledge. Information does not clear doubts or remove uncertainties, it demands the "reconstruction" of knowledge to the extent that it destroys certainties. (ALMEIDA: 2008a).

As far as Information Science is concerned, the Sociocultural Theory introduces the perspective of active subjects, the ones responsible for the construction of their own knowledge considering their life history and the environment surrounding them, the action subjects perform in a conscious or an unconscious way, as learning and development occur in an increasing and cooperative manner.

It is this active subject that should be transmuted into the user, a largely discussed figure in the literature of Information Science. The user to whom services are designed according to scientific conventions and standards, which often overlook the real needs of the target audience, limited as they are the only ones to the formalism of logic and the rational organization of knowledge.

The concern with the record and the support not only limits the possibilities of user growth, but also undermines informal practices, free activities in which documental record is a secondary objective.

Thus, collective action untied from compulsory results allows for the emergence of learning processes that are more creative and, above all, closer to the reality of the subjects involved in the research. We point out that the key action is the one generated by the support offered, in other words, the imbalance movement a given support causes in the subjects leading them to seek new ways and new approaches to troubleshooting and the way they act upon the world.

It is important to realize that every social organization is structured under the guidance of informational content, whether verbal or non verbal, being the action of the communication media directed at these contents. There is a flow of information and a process of information disclosure, but the fruit harvested in the process does not cause the development of the environment itself, but of each individual and the group as a whole. There is often a prejudgment about older adults in the face of technologies and the perpetuation of their difficulties in dealing with new technological content, which is not entirely true.

Information is the element that, once incorporated into the subject's reality, causes some effect. If it presents a content similar to the subject's field of knowledge, this information is incorporated and assimilated. Otherwise, it will lead the subjects to work on what stands out as different, in order to understand the differences and grasp their meaning.

Thus, information that is new or unaltered adopts the same mechanism of circulation in the society and the dissemination of such information spreads through the entire process of concept building. It is this information that ensures arguments, that is tied in documents assembled by public authorities and that aids the subject s' development. Hence the importance of developing information dissemination practices without any value assignment, providing informational content so that users are able to evaluate what is appropriate and what is not.

The key is to enable and extend the means of access to varied informational content, providing the subjects a greater exposure to the new and the unaltered, thus 
improving their ability to observe reality from a critical standpoint, with a reflective stance, thereby changing the focus of the information producer.

A greater amount of informational content implies that information producers come from various sources, from mass media to even a retired man living in a remote town, who one day had the courage to tell his story in a simple cordel ${ }^{l}$. The role of the information professional is exactly to expand access, giving voice to individuals, to small communities, because the outsider's view is always loaded with historically built concepts and the inner view is different. When we turn our attention to older adults, this difference becomes even greater. The point of view of older adults is the particular viewpoint of history, the information perspective that is frequently not recorded in literature but is rich, for it carries the particularities and peculiarities of its development, region, beliefs, fears, affections, of its living history.

The attitude required to aim for changes is sustained by the confidence or boldness only properly informed subjects can achieve. A currently accepted concept indicates that being informed is attaining power. And for older adults, information acquisition can be highly favorable as a mechanism to retrieve social action, since human aging brings about loss in social positions. Stimulation of older adults through information restores their autonomy and ensures the maintenance of their social status, as well as the protection of their individual rights.

Regarding the importance of actions in the face of problems, and the role of information in this context, Giglio says:

\begin{abstract}
We feel a natural urge to start looking for information whenever we face a problem. We intuitively know that the more we know about what challenges us, the greater our chances to confront them. Studies on creative processes and troubleshooting give special emphasis to information precisely because the greater a person's range of knowledge is, probably the more qualified he or she will be to address unforeseen situations. (GIGLIO: 2007).
\end{abstract}

The author points out the natural need every human being posesses to seek information, more specifically when facing a crisis. And the greater the amount of information, the greater the chances of solving problems.

Information expands the perspectives with which subjects view reality. And there is nothing more beneficial to older adults than the possibility of regaining their view of reality with the perspective of possibilities and challenges for future constructions.

\footnotetext{
1 "Literatura de cordel", or Cordel literature, is named for the way it is displayed by street vendors and at fairs in the northeast region of Brazil: hanging from a string. They are produced as inexpensive pamphlets or booklets and often illustrated with woodcuts. ( www.mariabrazil.org/cordel.htm)
} 


\section{METHODOLOGICAL COURSE}

A lot of input gives rise to academic research. This research has emerged from the observation and interaction with older adults as participants of the UNATI-UNESP, campus of Marília and as attendees of the reading workshop offered as an activity of the university extension project (Paiva \& Del-Masso: 2007). For seven years, it was in this environment of reading mediation that we had the opportunity not only to be in contact with the task of information mediation, but also to come close to conflicts, fears, achievements and projects that each student carried along. In these meetings, we have not only looked into social, cultural or literary information, but also mediated "what it was", "what it is", "what to do" and "how to do it" through reviewing notions, breaking taboos and myths, rebuilding new concepts. Then, in one of these meetings, we heard from one of the reading workshop attendees and a UNATI student the following statement: "I was brought up with 19th century concepts, grew up in the 20th century and grow old in the 21st century, what do I do with all these things I do not know how to handle?".

All these "things I do not know how to handle" (emphasis added) refers to equipment and instruments that comprise technological and informational supports, and that, in turn, pose real challenges to a significant portion of the population. In the particular case of older adults, this is a concrete, tangible problem, and a constant cause of protests contrary to the use of so many technological gadgets. The observation of such concerns has motivated our desire of carrying out research on the relationship between older adults and all those devices they did not know how to handle. However, these devices are not completely unknown to older people, they are things that just do not belong to their personal routines, objects that their eyes, hands, ears have not learned to "read" as yet. And only a closer reading of these objects will narrow the gap between older adults and "these things I do not know how to handle" (emphasis added). Such an approach could ease the lives of those who complain when interacting in an environment full of things they just do not know how to handle, but are influencing the way the modern man relates not only with his peers but also with the surrounding environment.

From this perspective, it is important to note which strategies can be more useful as aids in the process of bringing older adults closer to new reading supports, in this case, particularly computers and informational content supported by it, the Internet.

The Conto Prosa $\mathrm{blog}^{2}$ - a journal in an on-line environment

Proposing the switch from a textual record to an on-line collaborative environment requires strategies, considering that the group operates two information transmission formats - print text and digital content. Over a print text, linearity prevails; in a digital content, there is a fusion of multiple formats; disruption in a textual sequence and a new structuring of the support object require new forms of subject/object relationship.

In the process of planning a mediation strategy through art in the Internet environment, it was necessary to choose a format capable of supporting more

\footnotetext{
${ }^{2}$ Available at: http://contoprosa.blogspot.com.br/
} 
independent, open and democratic processes of creation and dissemination. A format closer to the language used in the Conto Prosa journal, charcterized by a simple, direct structure as well as a simplified language and commands. The participants of the reading workshop would be concerned with the availability of content, the attractiveness of the ways to disseminate their private messages and the fact that the environment should help and invite participants to handle, to unveil this new informational world.

The tool of choice for presenting such a simplified usage structure was the blog, a journal written on-line with updating policies defined by its users. The choice of this tool has fulfilled the goals of the research since it is a handy tool with a structure that is simple to be explained and understood, easy to read and grasp, thus meeting the objectives proposed for this research, without leaving aside the usage needs of the participants. Therefore, we sought for an approach loaded with meaning and relevance to the community which we dealt with.

To create the blog, it was not enough to teach the procedures for the tool's proper functioning. The experience with the group proved it to be necessary to bring content and support closer to its realities. As for the text discussions, the process was pretty much the same. The creative elements that emerged in the reading workshop resulted from a continuous connection between the subjects and the book support. There is the need of bringing the participant closer to the author's universe and to the ideas presented by him ; that is, an immersion in a context often different from the context in which they currently are. This interaction gives rise to discussions, creations. We thus state that it is not only about reading stories, the subjects involved are also capable of writing them.

It can be no different as far as computers and the Internet are concerned. First of all, the individual must be able to handle the machine, since computers are nothing more than an extension of human abilities enclosed in a case. It is therefore necessary to allow participants to become familiar with the world of computers and the Internet reading and reading anew on a constant basis, in this way leading them to realize what their possibilities, their resources, their reach are. Finally, it is about working with whatever is particular to them, reflecting on it and finding out which creative possibilities will arise in the migration from off-line to on-line universe. Once in the blog, they should manipulate it so as to give it features that are close to the group, dealing with content so that the subjects' values and references are revealed and registered through the texts.

The blog content comprised texts produced for the journal which were revised through another participative process, reading again but this time with virtual eyes. Various viewpoints on the same object, the text and its multiple forms of dissemination.

So as to guarantee familiarity with the support offered, in order to promote digital inclusion, we proposed the creation of a workshop extended to the UNATI students that took part in the reading workshop so that they could get acquainted with this new proposal. The following structure was set out for the development of the activities in the workshop: 


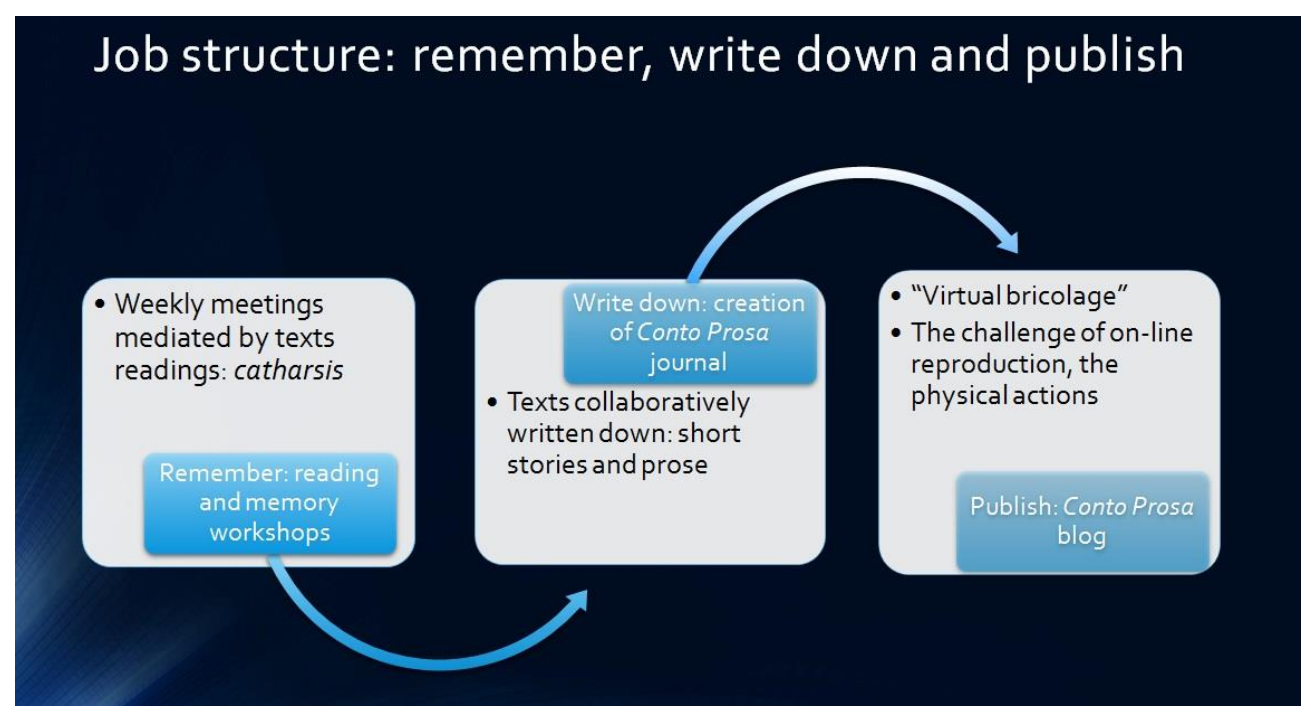

Figure 1: Job structure for the publishing of Conto Prosa blog

Weekly meetings - Weekly meetings ensured smaller intervals of work and a better interaction between the participants and the workshop.

Text reading and discussion - Texts were used to clarify doubts about the terms used on the Internet, the development of computers and the current stage of the Internet. The moments of text discussion were carried out in the first meetings of the reading workshop, featuring more theoretical traits.

Group dynamics - Group dynamics were used as recreational activities to explain concepts and carried out in the first meetings. Group dynamics were created based on the attendees' needs.

Computer usage - Participants had contact with computers starting from the 4th meeting. UNATI provided three computers for students usage to create the blog. To carry out the activities, students were divided into groups and each group was assigned a computer and a set of activities. 


\section{FINAL CONSIDERATIONS}

Scientific research is a path to be followed and, as such, it reveals several aspects related to each subject's maturation process. Soon research focus was shifted since, beyond practical, quantifiable results, a collaborative creation of a research project was sought after.

Supportting tools play a dominant role in the subject's learning and development processes. This is why activities should excel at perceiving the support as an actioninstigating instrument. It is not only a means, it acts upon knowledge construction processes.

In developing digital inclusion initiatives, one must not take into account only the product, as it is ephemeral, and what guarantees its transience is precisely the possibility of reinvention operated by the subjects.

One must therefore excel at actions that, by introducing flexible structures, allow the emergence of more creative learning processes, and above all closer to the reality of the subjects involved in the research.

There is a need to reflect on the relationships between information and personal empowerment ${ }^{3}$; we must therefore promote digital inclusion initiatives that enable older people to act so as to restore their autonomy, undertaking the maintenance of their social status, ensuring protection for their personal and social rights.

Mediation was presented throughout this work as an action that, by introducing an intermediate element in a stimulus-response relation, causes disruption and generates a reorganization that tends to a state of equilibrium.

Looking at a person's life, from their historical horizon, has allowed our study to understand the importance of the time factor in each subject's maturation process. Thus, the research focus was not only the practical, quantifiable results, but the collaborative creation of a research project aimed at registering the historical path of a collective activity with new challenges posed to this group.

In the context of the reading workshop, we have found out that there has been a physical relationship between the subjects, the supports, the contents and other society members. In the process of focusing on the subject/support, we realised that physical contact was necessary. Usage has allowed the subjects to mold the support, giving it characteristics that are favorable to them. This situation is described by Vygotsky (2000) when dealing with the importance of work done by men/women in handling instruments. Work in this context does not refer only to what provides for a living, but to an action that remodels and updates people who reinvent an instrument while working with it.

One must remember that support plays a dominant role in the process of subject's learning and development process. Therefore, activities should excel at perceiving the support as an action-instigating instrument. We have noticed that, in group activities,

\footnotetext{
${ }^{3}$ Personal empowerment enables individuals with increased autonomy and freedom.
} 
supporting tools served initially as action magnets. However, as activities developed, support was diverted from action so that new behaviors and actions could be experienced, thus revealing the subjects' preferences. We found out that, regardless of the support functionality, the relevance between its usage and the subject's way of living would guide the choice. It is the subjects who indicate what their needs are and how they will or will not use a given informational support, whether intended for reading or for similar activities.

We believe that cultural or information dissemination activities should be devised in order to meet the needs of individuals and groups. The difference between them is that, in the second case, one must acknowledge each subject's particular universe and then conceive it in the group context.

Group environments already provide the structure of needed instability for the Zone of Proximal Development, as quoted by Vygotsky (2000), to occur. But group activities provide a greater degree of poor adjustment. External signs are of different orders in a group activity. The book, the text, the personal opinion, the opinion of others, the agreement or disagreement, the reactions, the memories, ultimately the stimuli are generated by different sources, sometimes reinforcing initial standpoint, sometimes dismantling an entire rational order.

Information professionals' main concern in the development of products and services should not be focused on the final product, since we deal with the idea that individuals build their knowledge from a sociocultural process full of stimuli.

The documentary record does not portray all the informational and cognizant chain in which subjects build their histories; the result registered there was only a topical reference. Therefore, we believe that activities of cultural action should not be treated as informational products, but as actions that enhance a subject's development. We must remember not to focus on the product, as it is ephemeral, and what guarantees its transience is precisely the possibility of reinvention operated by the subjects. We must also remember that it is through work that individuals renew their knowledge and the action of creation and recreation is constantly made possible through action, unveiling a new world of possibilities mediated by varied informational means. 


\section{REFERENCES}

Almeida Junior , O. F.( 2008) Mediação da Informação: ampliando o conceito de disseminação. In: VALENTIN, M. (Org). Gestão da Informação e do conhecimento. São Paulo: Polis \& Cultura Acadêmica,

Beauvoir, S. (1970). A velhice. São Paulo: Difel.

Bosi, E. (1998). Memória e sociedade: lembranças de velhos. São Paulo: Companhia das Letras,

Giglio, Z. G.(2007) A criatividade e os caminhos: em busca do mapa no processo de envelhecimento. In: Bruns, M. A. de T \& Del-Masso, M.C.S. Envelhecimento humano: diferentes perspectivas. Campinas, SP: Editora Alínea

Paiva, S.B \& Del-Masso, M. C. S. Envelhecimento humano: leitura e memória. In: Bruns, M. A. de T \& Del-Masso, M.C.S. Envelhecimento humano: diferentes perspectivas. Campinas, SP: Editora Alínea, 2007. p.53-72.

Thiollent, M.(1988) Metodologia da pesquisa-ação. São Paulo: Cortez.

Vygotsky, L. S. (2000). A formação social da mente: o desenvolvimento dos processos psicológicos superiores. São Paulo: Martins Fontes. 